\title{
Crevice Corrosion of Several Supper Stainless Steels in the Simulated LT-MED Environment
}

\author{
Chang-Gang Wang ${ }^{1} \cdot \mathrm{Xiao}^{-F a n g} \mathrm{Li}^{1} \cdot$ Jie Wei ${ }^{1} \cdot \mathrm{Xin} \mathrm{Wei}^{1} \cdot$ Fang Xue ${ }^{1} \cdot$ Rong-Yao Ma $^{1} \cdot$ Jun-Hua Dong ${ }^{1} \cdot$ \\ Wei $\mathrm{Ke}^{1}$
}

Received: 1 January 2018/Revised: 31 January 2018/Published online: 27 April 2018

(C) The Chinese Society for Metals and Springer-Verlag GmbH Germany, part of Springer Nature 2018

\begin{abstract}
Susceptibility and morphological characteristics of crevice corrosion for SS316, SS904L, SS254sMo and SS2507 in the simulated low-temperature multi-effect distillation environment were investigated by cyclic polarization test, scanning electron microscope and laser microscope. The results show that the crevice corrosion resistance of four kinds of stainless steel is ranked as SS254sMo $\approx$ SS2507 > SS316 > SS904L. There are "cover" structures over the edge of active crevice corrosion regions of SS904L, SS254sMo and SS2507, but SS316 is an exception. Galvanic corrosion characteristics appeared in the crevice of duplex supper stainless steel SS2507.
\end{abstract}

Keywords Supper austenite stainless steel $\cdot$ Super duplex stainless steel $\cdot$ Low-temperature multi-effect distillation (LTMED) · Crevice corrosion · "Cover" structure

\section{Introduction}

Due to the uneven distribution of fresh water resources, many countries and regions all over the world are experiencing water shortage. As a technology to increase fresh water supply, desalination has become an important method to solve the crisis of water resource shortage $[1,2]$. Several technologies such as low-temperature multi-effect distillation (LT-MED), multistage flash distillation and reverse osmosis are used in the desalination process [3-6]. Among these, LT-MED is one of the most efficient thermal desalination technologies, which run at the temperature below $75{ }^{\circ} \mathrm{C}$ and produce a lot of high concentrated seawater [2]. In such a harsh corrosive environment, materials used for LT-MED equipment often suffer from serious corrosion damage.

Supper stainless steels are being increasingly used as structural materials in desalination facilities, due to their high resistance to local corrosion and stress corrosion

Available online at http://link.springer.com/journal/40195

Jun-Hua Dong

jhdong@imr.ac.cn

1 Institute of Metal Research, Chinese Academy of Sciences, Shenyang 110016, China cracking as well as their high strength and toughness [7, 8]. The high corrosion resistance of supper stainless steels comes from their high alloy contents, such as chromium, molybdenum and nitrogen, which can stabilize the passive film of stainless steels [9]. Based on the contribution of the three kinds of alloying elements, pitting resistance equivalent number (PREN) is used as a criterion to evaluate the stability properties of passive films, as shown in Formula (1) [9-11]. Normally, supper stainless steels have high values of PREN, and some of them can even exceed 40 (SS254sMo and SS2507, etc.).

$\mathrm{PREN}=1 \mathrm{Cr} \%+3.3 \mathrm{Mo} \%+30 \mathrm{~N} \%$.

Austenite and duplex supper stainless steels are two main types of supper stainless steels. Austenite supper stainless steels (SS904L and SS254sMo, etc.) are made up of austenite phase. Their corrosion behaviors are similar to SS316, while the corrosion resistances are much higher than it [12]. Duplex supper stainless steels (SS2507, etc.) composed of ferrite $(\alpha)$ and austenite $(\gamma)$ phase offer high strength and corrosion resistance, particularly pitting and crevice corrosion [13, 14]. In recent years, duplex supper stainless steels, characterized by their lower nickel contents, have attracted a lot of attention.

Currently, there have been a number of studies on the application evaluation of supper stainless steel to 
desalination equipment. Oldfield and Todd reported that, compared with ordinary stainless steel (SS316 and SS317, etc.), supper stainless steel (SS31254, etc.) was more able to meet the requirements of seawater reverse osmosis equipment for corrosion resistance [15]. However, in the case of screws and flanges, crevice corrosion is still impossible to avoid at the interface between the tightly contacted plate and the screw or flanges made up of supper stainless steel. For example, Wallen et al. found that flanges made of SS254sMo suffer severe crevice corrosion in continuously chlorinated seawater at $45{ }^{\circ} \mathrm{C}$, while the longitudinally welded pipes made of SS254sMo did not suffer any corrosion [16]. Mahk et al. [16] considered that, in seawater reverse osmosis equipment, SS2507 and SS254sMo have high resistance to crevice corrosion.

The PREN indexes of SS2507 and SS254sMo are significantly higher than that of SS904L, while the cost of SS904L was lower than those of the former two. Therefore, compared with SS2507 and SS254sMo, there are more promising applications in LT-MED equipment for SS904L. However, the application evaluation of the crevice corrosion resistance for SS904L, SS2507 and SS254sMo in LTMED equipment has not been reported.

SS904L, SS254sMo and SS2507 are the main candidates for LT-MED equipment, while there are still some crevice corrosion problems and they need to be clarified. For example, there is obvious difference between austenite (SS904L and SS254sMo, etc.) and duplex (SS2507, etc.) supper stainless steel in phase composition. Whether the crevice corrosion characteristics will be affected by the difference between the two phases and whether this phenomenon will limit their use in LT-MED equipment are still lack of knowledge. Moreover, the PREN of SS904L is greater than ordinary stainless steel (SS316), while its cost is obviously lower than that the supper stainless steel with high PREN (SS254sMo, etc.). Therefore, there are more promising applications in LT-MED equipment for SS904L. However, the evaluation on crevice corrosion for SS904L using for LT-MED equipment has not been carried out.

In view of the above problems, the aim of this work is to examine the crevice corrosion sensitivity of SS904L, SS254sMo and SS2507 and meanwhile assess their suitability for LT-MED equipment. In addition, this work is to reveal the crevice corrosion morphological characteristics of austenite (SS904L and SS254sMo, etc.) and duplex (SS2507, etc.) supper stainless steel.

\section{Experimental}

The chemical compositions and the metallographic morphologies of SS316, SS904L, SS254sMo and SS2507 used in this research are given in Table 1 and Fig. 1. SS316,
SS904L and SS254sMo are austenitic stainless steel consisting of single $\gamma$-phase, while SS2507 is duplex stainless steel composed of $\alpha$-phase and $\gamma$-phase. A multiple crevice assembly based on the standard guide for crevice corrosion testing, ASTM G78 [17, 18], was used. The modified crevice formers as shown in Fig. 2a were made up of polyethylene. There are 20 of plateaus on every multiple crevice assembly, and the design details of multiple crevice assembly can be seen from Fig. 2a. The stainless steel specimens $(30 \mathrm{~mm} \times 30 \mathrm{~mm} \times 6 \mathrm{~mm}$ with a 7 -mm-diameter hole) were cut from commercial plates (Fig. 2b). Electrical connection to the specimens was established via an isolated $\mathrm{Cu}$ wire, and epoxy resin was used for insulation treatment of welding points. Before starting the crevice corrosion test, all the tested specimens were abraded with wet 2000 grit $\mathrm{SiC}$ paper, degreased with acetone followed by alcohol and then dried in air. The specimen assembly was tightened with a titanium bolt, nut and washer using a torque wrench with the applied torque of $0.1 \mathrm{Nm}[17,18]$, so that 20 small crevice sites were formed on each side of the specimen (Fig. 2c). PTFE tape was used to insulate the bolt to prevent electrical connection between the titanium bolt and the stainless steel specimen.

The crevice corrosion test was performed in two times concentrated artificial sea water, and the detailed compositions of the solution are given in Table $2[17,19]$. The test temperature is $70{ }^{\circ} \mathrm{C}$.

The standard three-electrode cyclic potentiodynamic polarization method was employed according to ASTM G61 [17, 20]. The test cell was composed of a reference electrode (saturated calomel electrode), a platinum sheet as the electrode $(20 \mathrm{~mm} \times 20 \mathrm{~mm})$ and a working electrode (stainless steel specimen assembly), as shown in Fig. 3. Prior to carrying out the cyclic potentiodynamic polarization test, the specimens were kept in solution for $30 \mathrm{~min}$. The scan was initiated from $100 \mathrm{mV}$ below the open-circuit potential (OCP) forward to $400 \mathrm{mV}_{\mathrm{SCE}}$ and then backward to $100 \mathrm{mV}$ below OCP. The sweep rate was controlled at $0.166 \mathrm{mV} / \mathrm{s}$.

All the electrochemical measurements were taken by using a Gamry 600 electrochemical workstation. The corrosion depth profile of the crevice corrosion site was measured using a LEXT laser microscope OLS 4000. The corrosion morphology was observed using a Phillips FEI INSPECTF scanning electronic microscope (SEM).

\section{Results and Discussion}

Figure 4 shows the cyclic potentiodynamic polarization curves of SS316, SS904L, SS254sMo and SS2507 crevice assembly specimens in the two times concentrated artificial seawater at $70{ }^{\circ} \mathrm{C}$. In the cyclic potentiodynamic 
Table 1 Chemical compositions of SS316, SS904L, SS254sMo and SS2507 stainless steels $(\mathrm{wt} \%)$

\begin{tabular}{lllllllllll}
\hline & $\mathrm{C}$ & $\mathrm{Cr}$ & $\mathrm{Ni}$ & $\mathrm{Mn}$ & $\mathrm{Si}$ & $\mathrm{P}$ & $\mathrm{S}$ & $\mathrm{Mo}$ & $\mathrm{N}$ & $\mathrm{Cu}$ \\
\hline SS316 & 0.05 & 16.9 & 10.6 & 1.6 & 0.5 & 0.031 & 0.006 & 2.05 & - & - \\
SS904L & 0.02 & 20.1 & 25.3 & 2.00 & 1.00 & 0.045 & 0.035 & 4.04 & - & 1.32 \\
SS254sMo & 0.02 & 19.7 & 17.8 & 1.0 & 0.8 & 0.03 & 0.01 & 6.2 & 0.19 & 0.75 \\
SS2507 & 0.03 & 25.4 & 7.01 & 1.00 & 0.80 & 0.035 & 0.020 & 4.2 & 0.27 & 0.50 \\
\hline
\end{tabular}
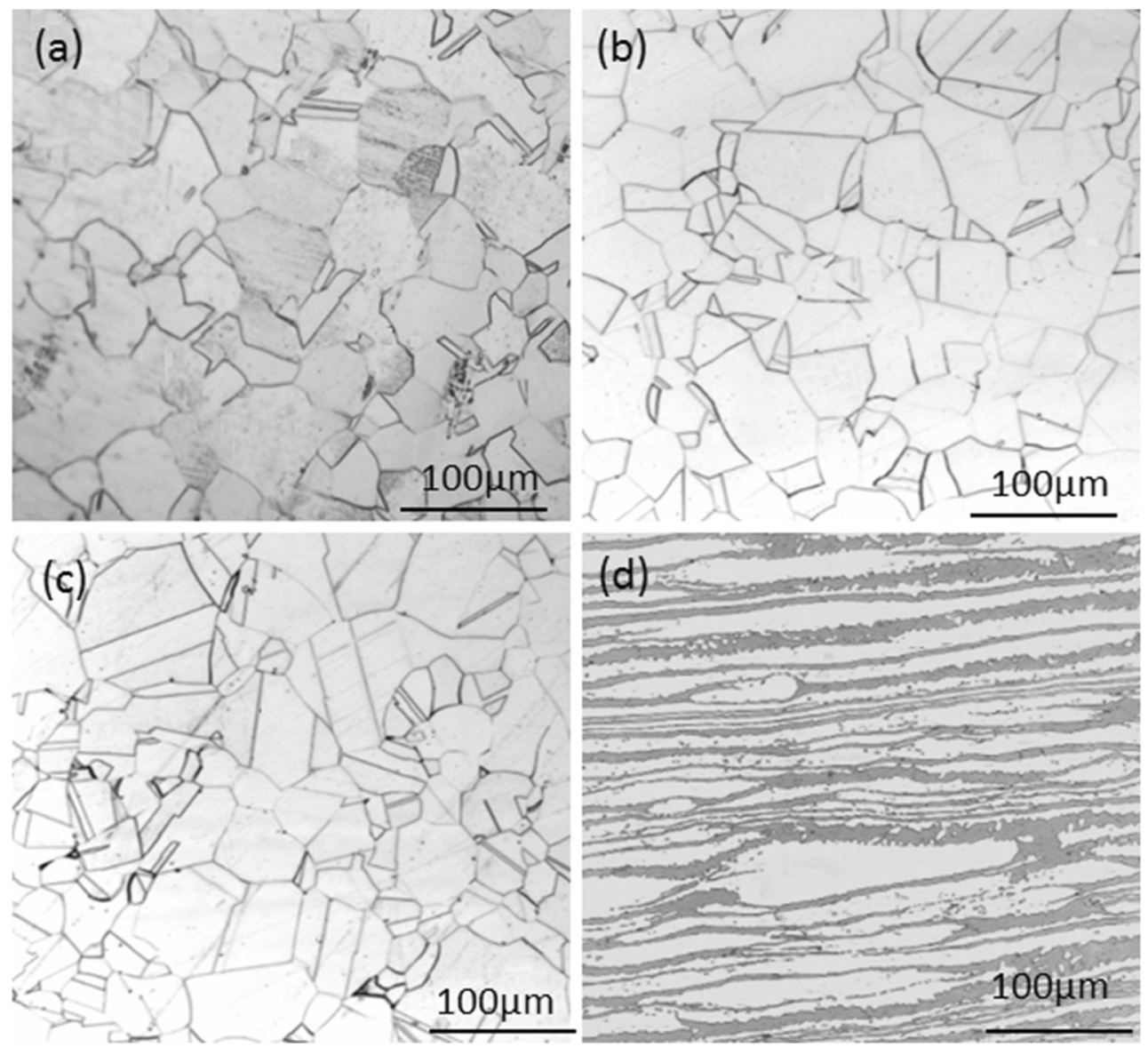

Fig. 1 Metallographic morphologies of a SS316, b SS904L, c SS254sMo, d SS2507 stainless steels

polarization curves, three important corrosion parameters which are, respectively, called as corrosion potential $\left(E_{\text {corr }}\right)$, breakdown potential $\left(E_{\mathrm{b}}\right)$ and repassivation potential $\left(E_{\mathrm{rp}}\right)$ can be seen. The values of $E_{\mathrm{corr}}, E_{\mathrm{b}}$ and $E_{\mathrm{rp}}$ for SS316, SS904L, SS254sMo and SS2507 stainless steels are shown in Table 3 . The measured $E_{\text {corr }}$ values are in the following sequence: SS316 $\left(-325 \mathrm{mV}_{\mathrm{SCE}}\right)<\mathrm{SS} 904 \mathrm{~L}$ $\left(-307 \mathrm{mV}_{\mathrm{SCE}}\right)<\mathrm{SS} 254 \mathrm{sMo}\left(-231 \mathrm{mV}_{\mathrm{SCE}}\right)<\mathrm{SS} 2507$ $\left(-213 \mathrm{mV}_{\mathrm{SCE}}\right)$, respectively. When the scanning potential reaches the breakdown potential $\left(E_{\mathrm{b}}\right)$, the passive film breaks down and localized corrosion occurs on the stainless steel surface. The more negative the breakdown potential $\left(E_{\mathrm{b}}\right)$ is, the easier for the initiation of localized corrosion (pitting or crevice corrosion) occurs [20]. Normally, this is attributed to the easier initiation for crevice corrosion than pitting corrosion, and the breakdown potential $\left(E_{\mathrm{b}}\right)$ of crevice corrosion is more negative than that one [21-23]. Therefore, the value of $E_{\mathrm{b}}$ is considered as the breakdown potential of crevice corrosion in this study. The measured $E_{\mathrm{b}}$ values of SS316, SS904L, SS254sMo and SS2507 crevice corrosion specimens are, respectively, 86, 114, 175 and $178 \mathrm{mV}_{\mathrm{SCE}}$, which mean that the susceptibility of crevice corrosion can be sequenced as follows: SS316 > SS904L $>$ SS254sMo $\approx$ SS2507. In addition, the reverse scanning curve intersects the forward scan curve at one point, and the potential of this point is called repassivation potential $\left(E_{\mathrm{rp}}\right)$ [24]. The more negative of this potential is, the more difficult to repassivate of the steel is [20]. The measured $E_{\mathrm{rp}}$ values of SS316, SS904L, SS254sMo and SS2507 crevice corrosion specimens are, respectively, 

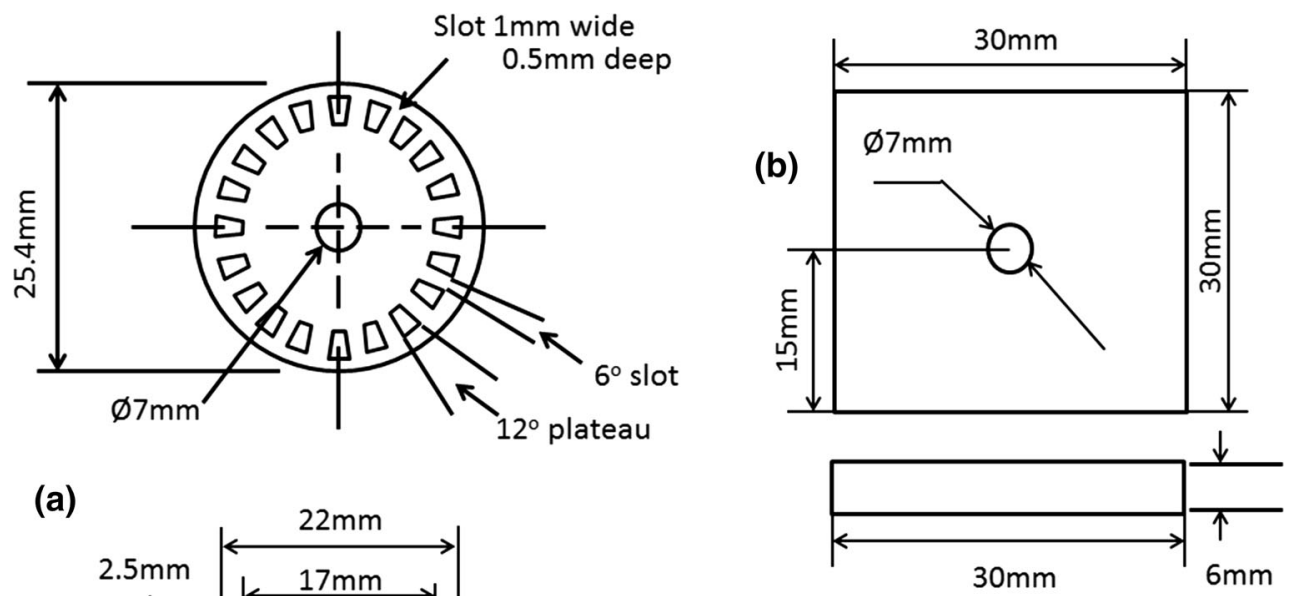

(a)

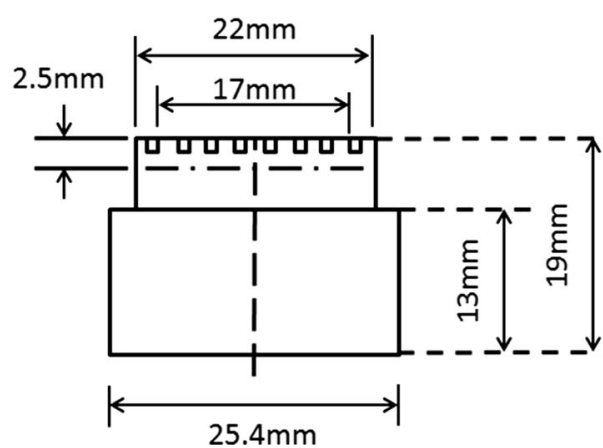

(c)

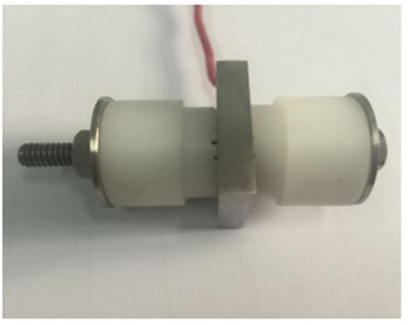

Fig. 2 Multiple crevice assembly with the specimen [13, 14]: a dimensions of crevice former; b dimensions of test specimen; c specimen assembly

Table 2 Compositions of the two times concentrated artificial seawater $(\mathrm{g} / \mathrm{L})$

\begin{tabular}{lllllll}
\hline $\mathrm{NaCl}$ & $\mathrm{MgCl}_{2}$ & $\mathrm{Na}_{2} \mathrm{SO}_{4}$ & $\mathrm{CaCl}_{2}$ & $\mathrm{NaHCO}_{3}$ & $\mathrm{KBr}$ & $\mathrm{H}_{3} \mathrm{BO}_{3}$ \\
\hline 49.06 & 10.4 & 8.18 & 2.32 & 0.402 & 0.202 & 0.054
\end{tabular}

$-373,-242,-189$ and $-165 \mathrm{mV}_{\mathrm{SCE}}$. It is necessary to concern that the value of $E_{\mathrm{rp}}$ is more negative than $E_{\text {corr }}$ for SS316, which means that SS316 occurs to crevice corrosion more easier [21, 25]. The value of $E_{\mathrm{rp}}$ is more positive than $E_{\text {corr }}$ for the other three kinds of stainless steels. The current densities on the polarization curve at $400 \mathrm{mV}_{\mathrm{SCE}}$ are in the following sequence: SS254sMo $(4.8 \mathrm{~mA})<$

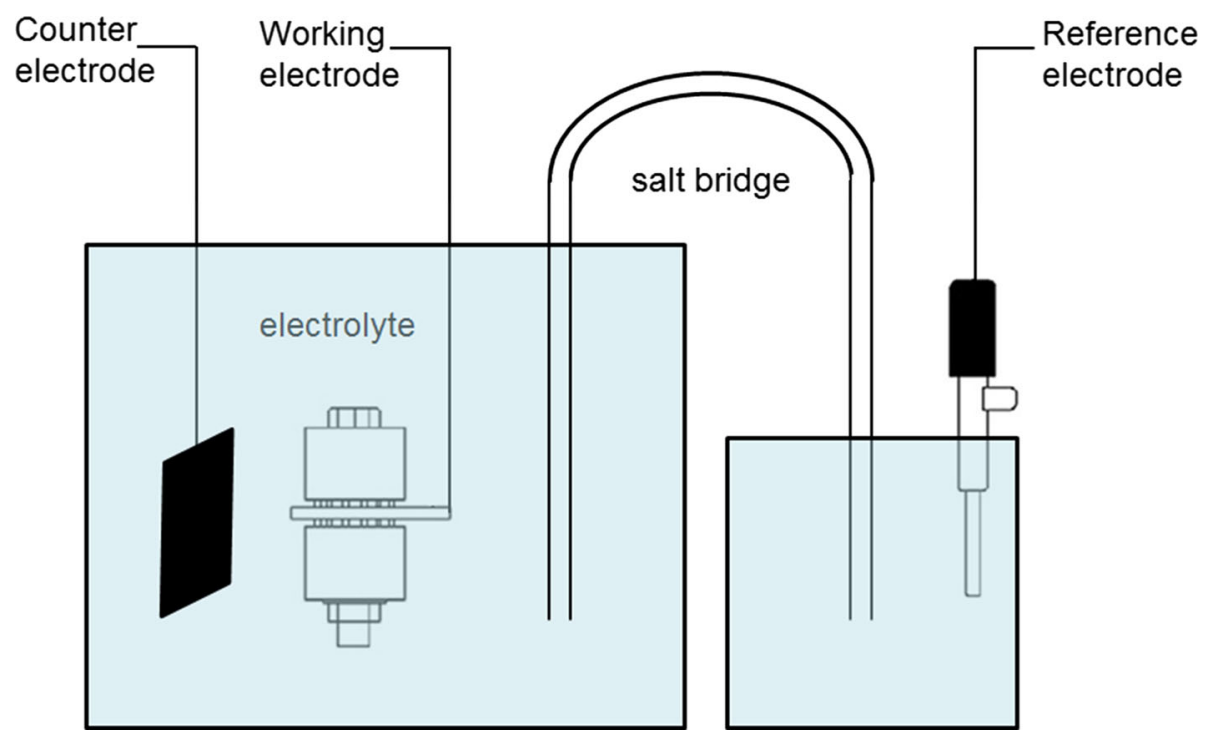

Fig. 3 Schematic diagram of the three-electrode test cell 

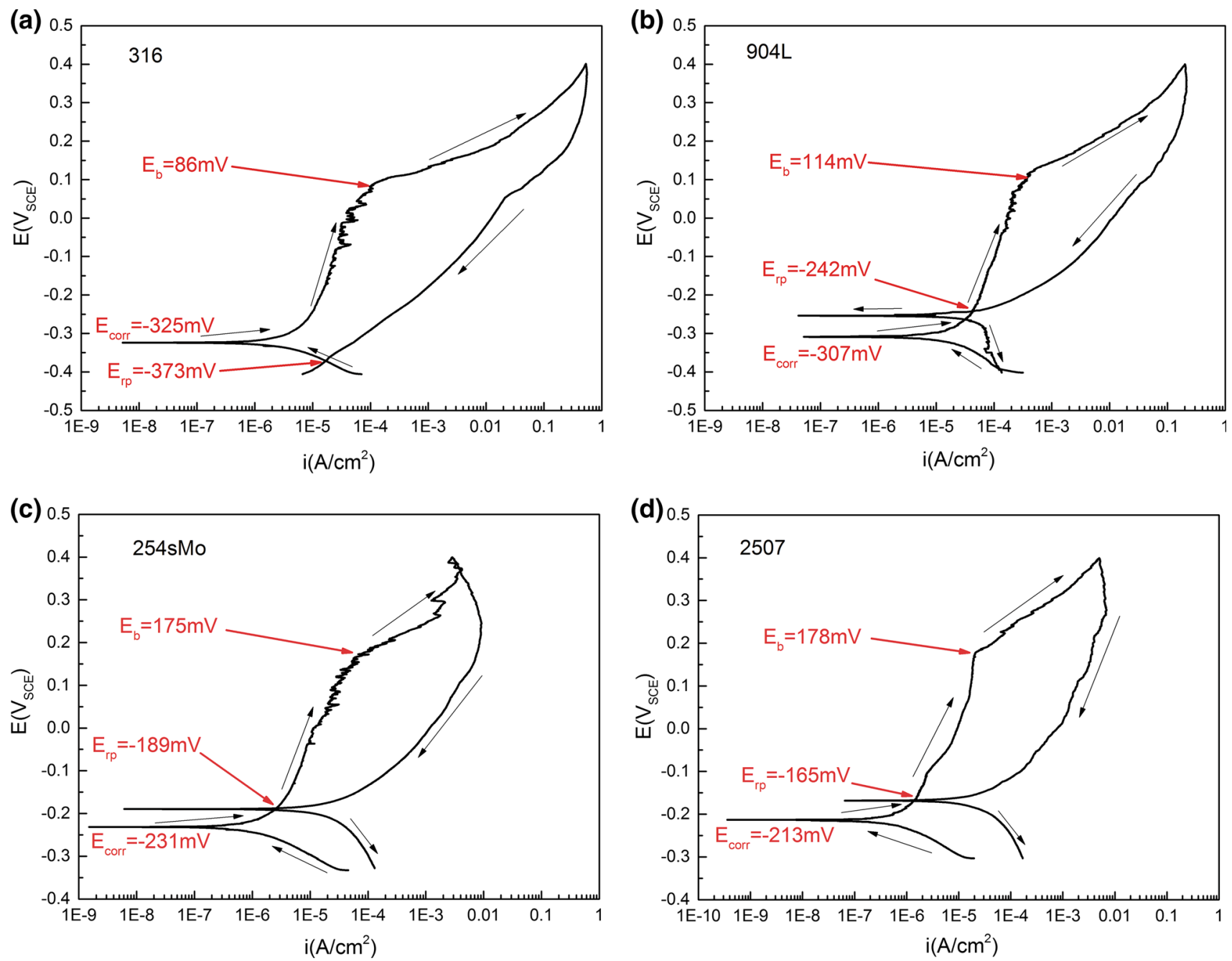

Fig. 4 Cyclic potentiodynamic polarization curves of a SS316, b SS904L, c SS254sMo, d SS2507 stainless steel crevice corrosion specimen in two times concentrated artificial seawater at $70^{\circ} \mathrm{C}$

Table 3 Parameter values of cyclic polarization curves of SS316, SS904L, SS254sMo and SS2507 stainless steels $\left(\mathrm{mV}_{\mathrm{SCE}}\right)$

\begin{tabular}{lcrl}
\hline & $E_{\text {corr }}$ & $E_{\mathrm{b}}$ & $E_{\text {rp }}$ \\
\hline SS316 & -325 & 86 & -373 \\
SS904L & -307 & 114 & -242 \\
SS254sMo & -231 & 175 & -189 \\
SS2507 & -213 & 178 & -165 \\
\hline
\end{tabular}

SS2507 $\quad(2.9 \mathrm{~mA})<\mathrm{SS} 904 \mathrm{~L} \quad(195.5 \mathrm{~mA})<\mathrm{SS} 316$ $(521.9 \mathrm{~mA})$, respectively, which mean that the corrosion damage to the surface of stainless steel is in the same order.

Figure 5 shows macromorphology of SS904L artificial crevice corrosion specimen and the depth measurement by laser microscope. Each artificial crevice specimen has 40 crevice sites, while not every crevice site was attacked during cyclic polarization testing. The number of crevice sites attacked by crevice corrosion reflects the crevice corrosion sensitivity of the stainless steel. The more locations of crevice sites were attacked by crevice corrosion, the poorer performance of stainless steel to resist crevice corrosion. Figure 6 shows the statistical diagram of the number of crevice sites attacked by crevice corrosion on four kinds of stainless steel after cyclic polarization testing. As can be seen from Fig. 6, the number of crevice sites attacked by crevice corrosion can be described with the following sequence: SS904L (31) $>$ SS316 (29) > SS254sMo (16) > SS2507 (14). In addition, the maximum depth of crevice corrosion can also reflect the resistance to crevice corrosion of stainless steel. Figure 7 shows the statistical diagram of the maximum depth of each crevice corrosion sites on four kinds of stainless steel. As shown in Fig. 7, the maximum depth of crevice corrosion sites can be described with the following sequence: SS904L > SS316 $>$ SS254sMo $>$ SS2507. The maximum crevice corrosion depths on SS904L and SS316 are larger than 140 


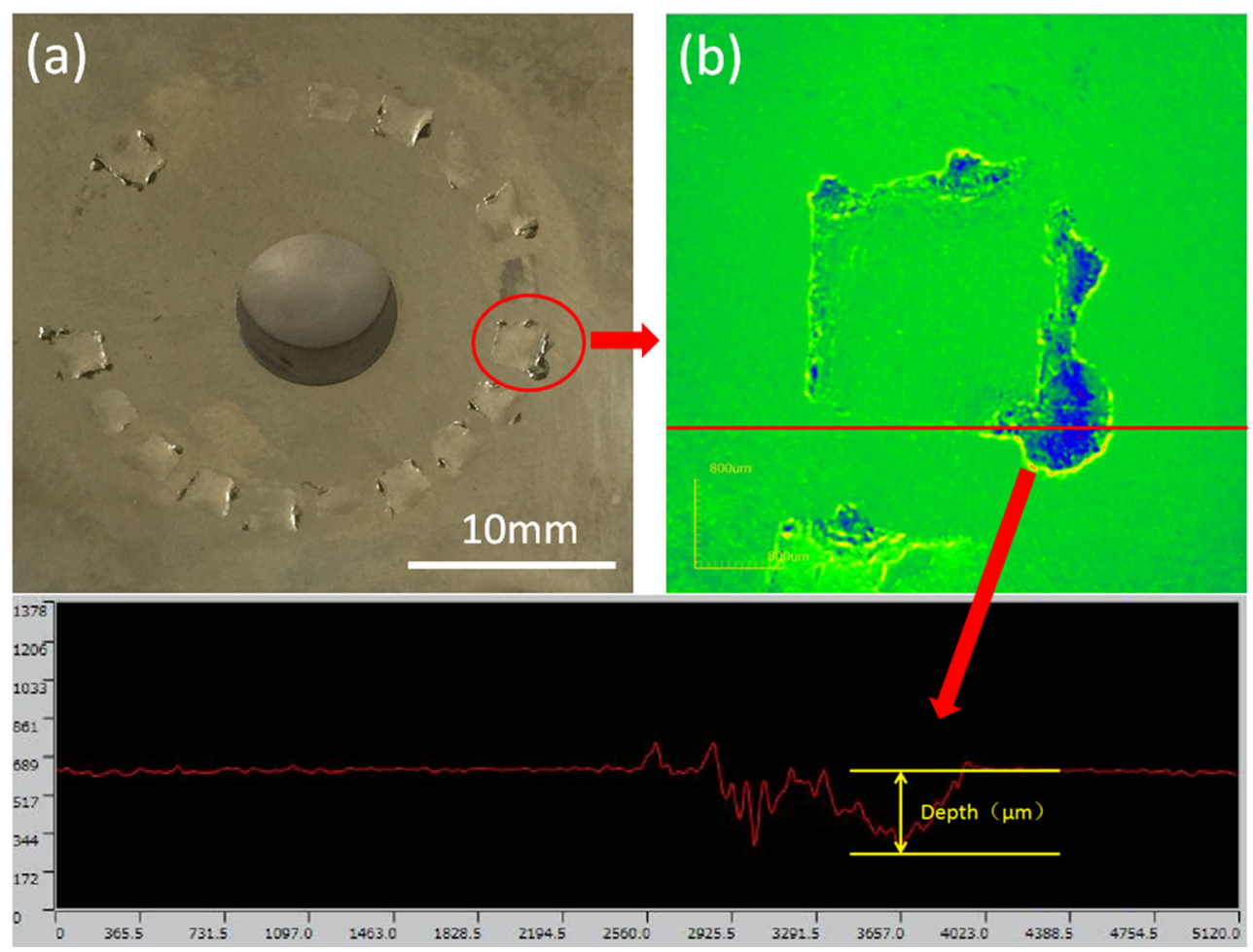

Fig. 5 Macromorphology of SS904L artificial crevice corrosion specimen a and picture of crevice depth measurement $\mathbf{b}$

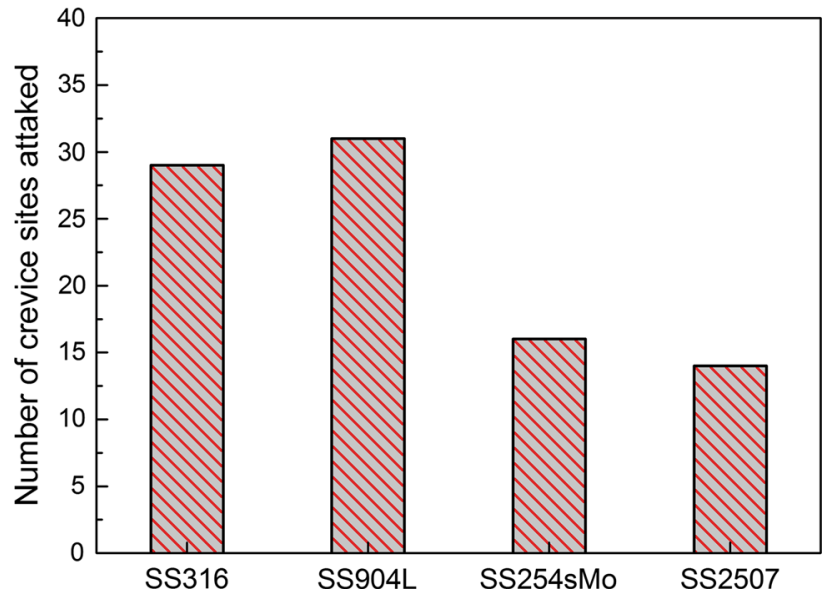

Fig. 6 Statistical diagram of the number of crevice sites attacked by crevice corrosion on four kinds of stainless steel after cyclic polarization testing

and $120 \mu \mathrm{m}$, respectively, which are significantly greater than SS254sMo and SS2507.

Figure 8 shows the sketch map of depth distribution of crevice corrosion [17]. According to the IR drop theory, three regions extending from the boundary of the crevice to the center inside the crevice can be classified: (A) passive region, (B) active region and (C) variable region [17, 26-28]. Meanwhile, the active region of crevice corrosion site on stainless steel consists of three subregions: $\left(B_{1}\right)$ severely attacked region, $\left(B_{2}\right)$ commonly attacked

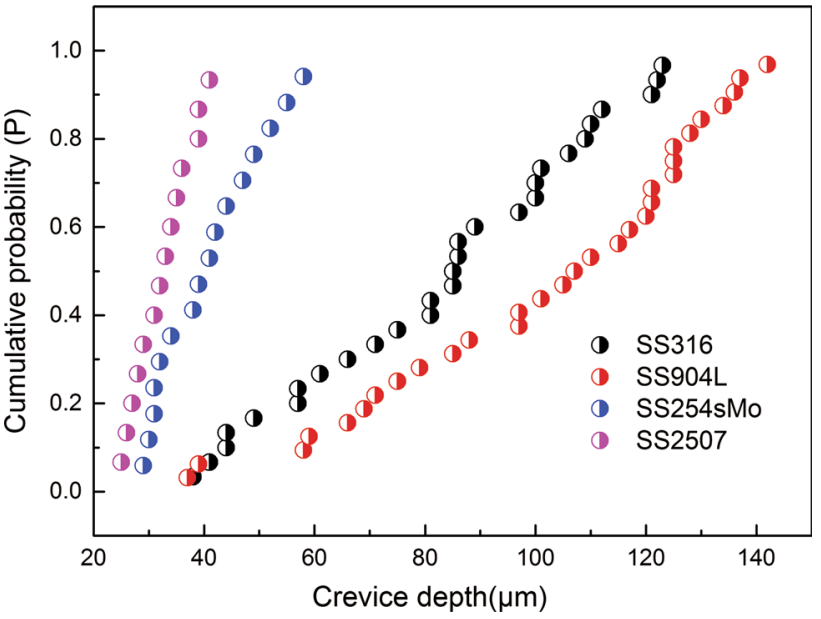

Fig. 7 Statistical diagram of the maximum depth of each crevice corrosion sites on four kinds of stainless steel

region and $\left(\mathrm{B}_{3}\right)$ lightly attacked region [17]. Surface morphologies of the four kinds of stainless steel crevice corrosion sites are further investigated by SEM, as shown in Figs. 9, 10, 11 and 12, respectively.

Figure 9a shows the morphology of a typical crevice corrosion site on SS316. Figure 9b shows the magnified morphology of the active region. Figure $9 \mathrm{c}-\mathrm{e}$ is local microscopic morphologies of the active region, respectively, called severely attacked region, commonly attacked region and lightly attacked region. As can be seen from 


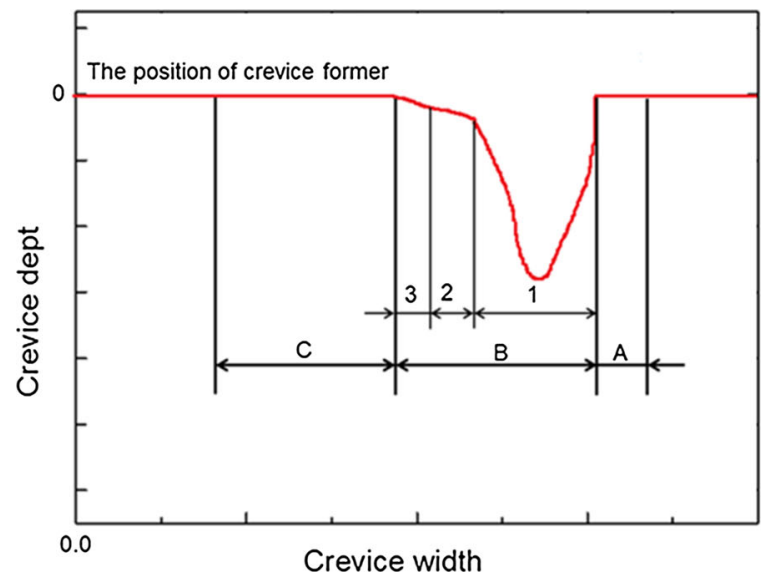

(A) Passive region
(B) Active region

1. Severely attacked region

2. Commonly attacked region

3. Lightly attacked region

(C) Variable region

Fig. 8 Sketch map of depth distribution of crevice corrosion [17]

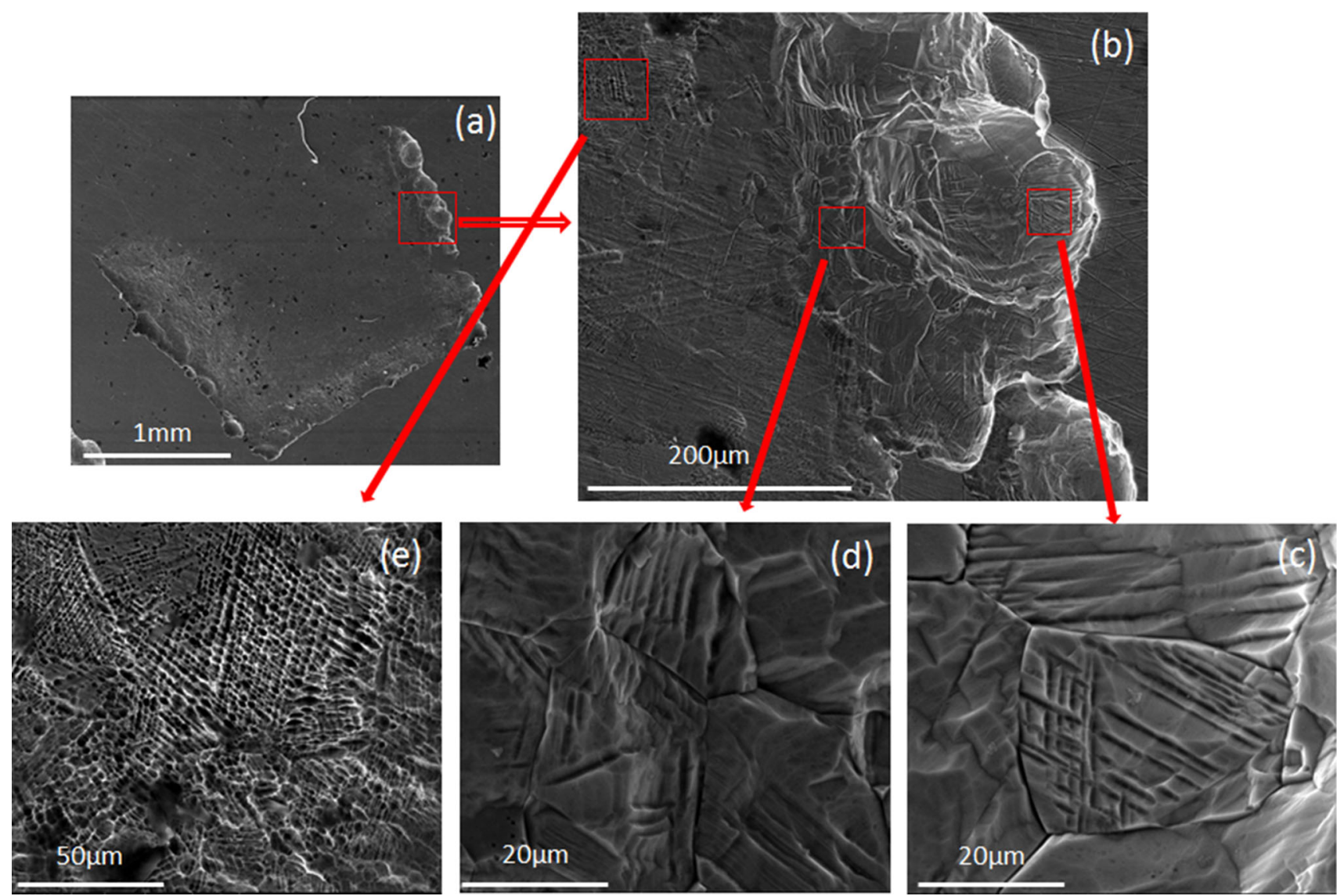

Fig. 9 SEM micrographs of different regions on a typical crevice corrosion site of SS316 after cyclic polarization testing

Fig. 9c, d, in the severely and commonly attacked region, austenite grain boundary is preferentially corroded, and there is ladder-like corrosion morphology on the grain surface. As shown in Fig. 9e, there is no austenite grain boundary on the surface of lightly attacked region and the corrosion morphology is dense ravine-like.

Figure 10a shows the morphology of a typical crevice corrosion site of SS904L, which also includes passive region, active region and variable region. It can be seen from the top right corner of the crevice corrosion site that there is a "cover" structure over the edge of the active region. Figure $10 \mathrm{~b}$ is the high-magnification morphology of "cover" structure. According to the EDS results from the red area of Fig. 10b, the "cover" structure is thin oxide slice composed of Fe, Cr, Mo and Ni elements (Fig. 10c), which is similar to the "lace cover" structure formed in the 


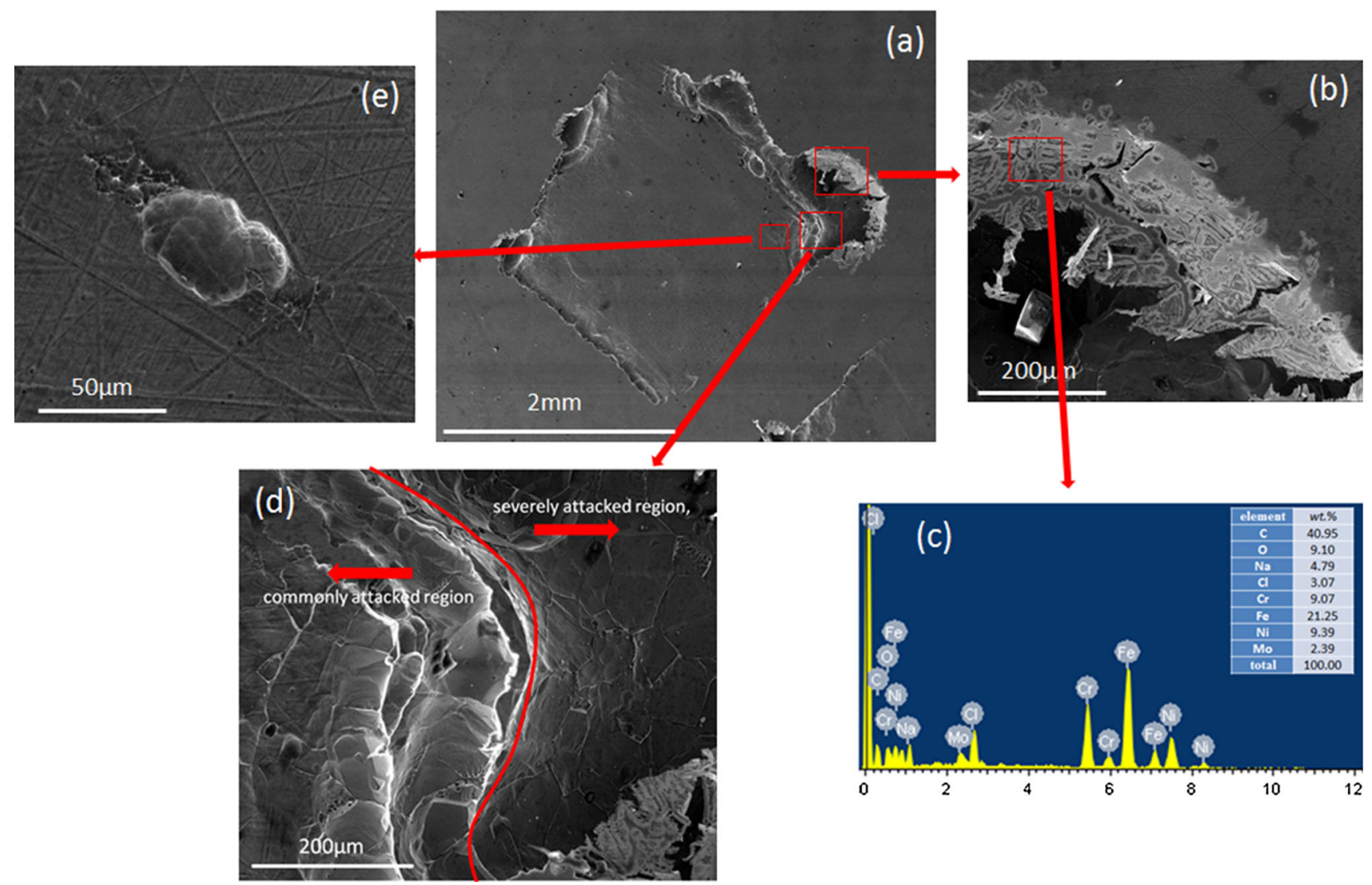

Fig. 10 SEM micrographs of different regions on a typical crevice corrosion site of SS904L after cyclic polarization testing

metastable pitting period of stainless steel [29]. As can be seen from Fig. 10d, the right and left parts of the picture should be the severely attacked region and the commonly attacked region, respectively. Their corrosion morphologies are similar to each other. Attributing to preferential corrosion, the austenite grain boundary is clearly visible, and the grain surface is relatively smooth. Figure 10e shows the corrosion morphology of lightly attacked region, and the friction scratches by sandpaper are still visible, illustrating that the corrosion is mild in this area. Some pits with the diameters of about $50 \mu \mathrm{m}$ are found, illustrating that the surface is prone to pitting corrosion in this area.

Figure 11a shows the morphology of a typical crevice corrosion site on SS254sMo. Figure 11b is the high-magnification morphology of active region. Being similar to SS904L, there is also "cover" structure over the edge of the active region. Figure 11c shows the high-magnification morphology of "cover" structure, the size of which is significantly smaller than that of SS904L. According to the EDS results from the red area in Fig. 11c, the "cover" structure is also thin oxide slice composed of $\mathrm{Fe}, \mathrm{Cr}$, Mo and Ni elements (Fig. 11d). Figure 10e-g shows the corrosion morphologies of severely, commonly and lightly attacked region, respectively. As can be seen from Fig. 11e, in the severely attacked region, austenite grain boundary is preferentially corroded and the grain surface is uneven. Figure 11f shows that the corrosion morphology of commonly attacked region is dense ravine-like, and the austenite grain boundary is also preferentially corroded. Figure $11 \mathrm{~g}$ shows the corrosion morphology of lightly attacked region. Being similar to SS904L, the friction scratches by sandpaper are visible, and some small size pits are also found in this area.

Figure 12a shows the corrosion morphology of a corner on a typical crevice corrosion site of SS2507. As can be seen from Fig. 12b, there is also "cover" structure over the edge of the active region. Being different from the thin oxide slice structures of SS904L and SS254sMo, the "cover" structure of 2507 stainless steel consists of many micron-sized small holes, which is more like the "lace cover" structure of metastable pitting in stainless steel morphologically [29, 30]. Figure 12c-e corresponds to the corrosion morphologies of severely, commonly and lightly attacked region, respectively. The phenomena of galvanic corrosion were observed in the three corrosion region. SS2507 is duplex stainless steel, which consists of ferrite phase $(\alpha)$ and austenite phase $(\gamma)$. Tsai and Chen [13] have fabricated single-phase electrodes of $\alpha$-phase and $\gamma$-phase from duplex stainless steel and studied the galvanic corrosion between two phases. They found that, in an acid solution containing $\mathrm{Cl}^{-}$, the corrosion potential of ferrite 


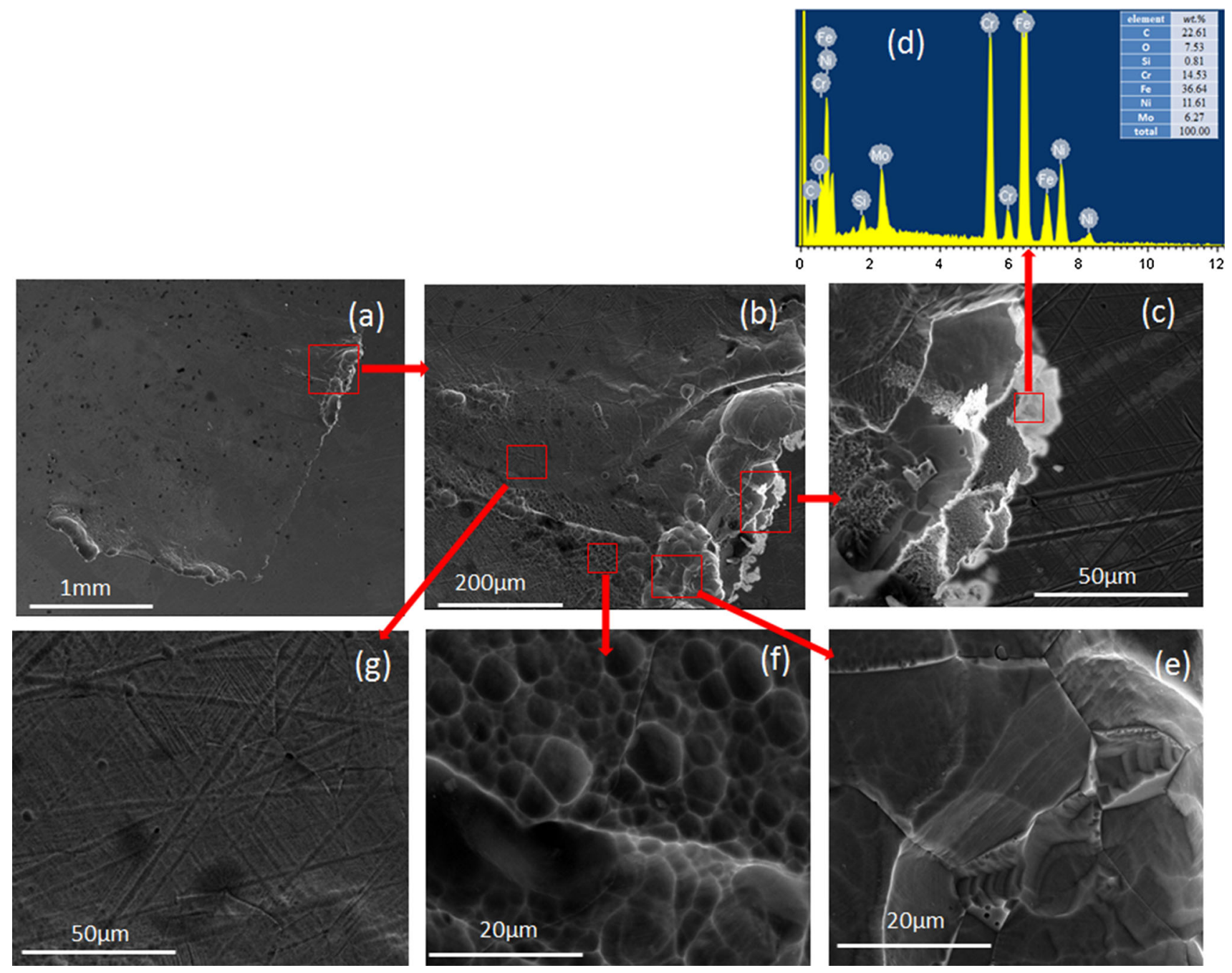

Fig. 11 SEM micrographs of different regions on a typical crevice corrosion site of SS254sMo after cyclic polarization testing

phase $(\alpha)$ is normally lower than that of austenite phase $(\gamma)$ and is preferentially corrosion as an anode phase [13]. The local environment of active region of crevice structure is also acid solution containing $\mathrm{Cl}^{-}$, and passive film was partly dissolved attributing to the local acidification. As the passive film gradually loses its protective properties, galvanic corrosion occurs between the two phases, and the ferrite phase $(\alpha)$ preferentially corroded, while austenite phase $(\gamma)$ remained. This result agrees with the previous related studies about corrosion resistance of duplex stainless steel $[13,31,32]$. As can be seen from Fig. 12c, the corrosion morphology on the surface of retained austenite phase $(\gamma)$ is honeycomb in severely attacked region. Figure $12 \mathrm{~d}$ shows that, in commonly attacked region, there is a great difference in corrosion depth between the two phases, which means that the galvanic corrosion is the most serious here. The corrosion damage is mild in lightly attacked region, and the friction scratches by sandpaper are also still visible, as shown in Fig. 9e.
Identifying from the statistical results of the number and depth of crevice corrosion pits, the most serious crevice corrosion occurred on SS904L followed by SS316, SS254sMo and SS2507 in the two times concentrated seawater at $70{ }^{\circ} \mathrm{C}$. Attributing to the high amounts of alloying elements, namely chromium, molybdenum and nitrogen, SS254sMo and SS2507 are called supper stainless steels, and their crevice corrosion resistances are remarkably superior to ordinary stainless steel SS316. However, being known as supper stainless steel, the crevice corrosion resistance of SS904L is interestingly not as good as ordinary stainless steel SS316.

From the observation of crevice corrosion microscopic morphology, the "cover" structures exist over the edge of the active region of all the three kinds of supper stainless steels. The "cover" structure is often observed in metastable pitting of stainless steel, which is called "lace cover," while rarely observed in the crevice corrosion process $[29,30]$. The classical study shows that, in the 


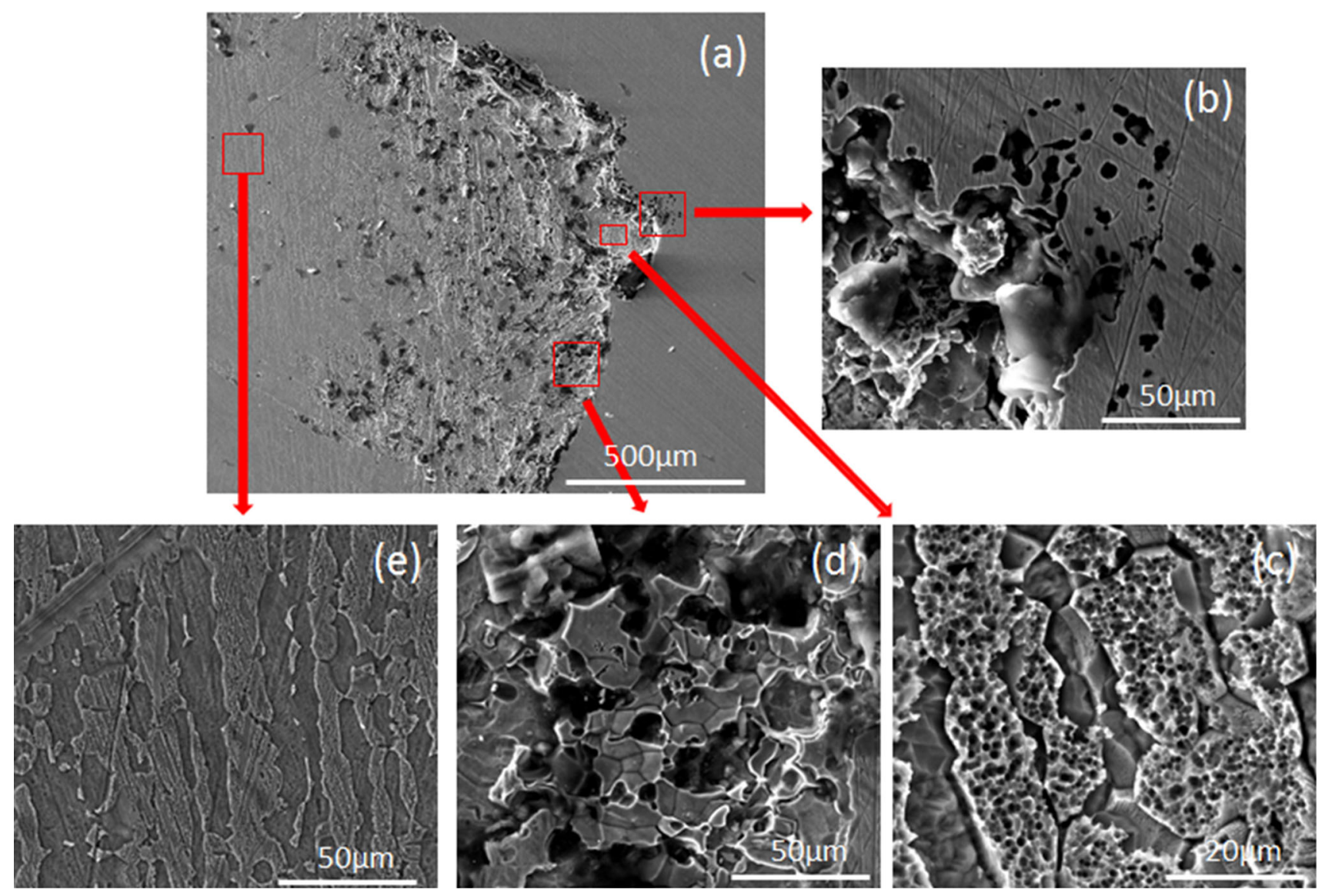

Fig. 12 SEM micrographs of different regions on a typical crevice corrosion site of SS2507 after cyclic polarization testing

process of transition from metastable to steady pitting of stainless steel, as an additional barrier for the ionic current passing through the pit anolyte and the exterior electrolyte, the "lace cover" could sustain pit growth [29]. According to the same principle, the "cover" structure can also accelerate the corrosion process of stainless steel in the crevice. Related studies show that the "cover" structure mainly consists of the passive film which had originally covered the unattacked metal [29]. It is known that alloying elements like chromium, molybdenum and nitrogen are favorable for the stabilization of passive film [8]. As the two primary forms of chromium, $\mathrm{CrOOH}$ can reduce the defects in the passive film, and $\mathrm{CrO}_{4}{ }^{2-}$ was found to be beneficial as potent inhibitor [8,33-35]. Molybdenum can induce the formation of a bipolar layer in the form of molybdate and promote the generation of $\mathrm{Cr}_{2} \mathrm{O}_{3}$ by accelerating the migration of $\mathrm{O}^{2-}$ [36-41]. Nitrogen can stabilize the passive film in the form of $\mathrm{NO}_{3}{ }^{-}$; meanwhile, $\mathrm{CrN}$ which is incorporated of nitride and bulk chromium could impede the dissolution of metal ions [42-47]. The PREN calculated by formula (1) can be described as the following sequence: SS316 $(22.665)<$ SS904L (33.432) $<$ SS254sMo $\quad(45.86) \approx \mathrm{SS} 2507 \quad$ (47.36).
Therefore, the passive film of SS316 is the most unstable, and there are "cover" structures over the edge of the active region of all the three kinds of supper stainless steel except SS316.

Taking into account the role of "cover" structure in accelerating crevice corrosion, the crevice corrosion resistance of the 316 stainless steel should be better than those of SS904L, SS254sMo and SS2507. However, the self-repairing ability of the passive film inside the crevice is another major factor affecting the development of crevice corrosion. According to the results of cyclic polarization curves, the order of self-repairing ability can be described with the following sequence: SS2507 > SS254sMo $>$ SS904L $>$ SS316. The self-repairing ability of the passive film also depends on the amounts of alloying elements chromium, molybdenum and nitrogen. Obviously, nitrogen in the form of $\mathrm{NO}_{3}{ }^{-}$plays the most important role in the process of repassivation [42-46]. Both SS254sMo and SS2507 contain trace amounts of nitrogen, and their PREN is much higher than those of SS316 and SS904L. That is why the resistances to crevice corrosion of SS254sMo and SS2507 are significantly better than those of SS316 and SS904L. The self-repair ability of passive 
film inside the crevice for SS904L is slightly better than SS316. Meanwhile, due to the barrier mass transfer effect of large-size "cover" structure, the crevice gap of SS904L is more blocked than that of SS316. Between the two opposing factors, the barrier mass transfer effect of largesize "cover" structure plays a more prominent role; thus, the crevice corrosion of SS904L is more serious than that of the SS316.

\section{Conclusions}

1. In the two times concentrated seawater at $70{ }^{\circ} \mathrm{C}$, the crevice corrosion occurred on the surface of all the three kinds of supper stainless steels. The crevice corrosion damage of SS904L is the most serious (even more serious than the ordinary stainless steel SS316), and those of SS254sMo and SS2507 stainless steel are the slightest.

2. Preferential corrosion in austenite grain boundary was observed in severely and commonly attacked regions of austenite stainless steels (SS316, SS904L and SS254s). The phenomena of galvanic corrosion were observed in the active crevice corrosion region of duplex supper stainless steel (SS2507), and the ferrite phase $(\alpha)$ was preferentially corroded, while the austenite phase $(\gamma)$ was remained.

3. Due to the stable passivation film of high-alloyed supper stainless steel, there are "cover" structures over the edge of active crevice corrosion regions of SS904L, SS254sMo and SS2507, but SS316 is an exception.

4. Attributing to the barrier mass transfer effect of largesize "cover" structure, the crevice gap of SS904L is more blocked than that of SS316, and thus, the crevice corrosion of SS904L is more serious than SS316.

Acknowledgements This work was financially supported by the National High Technology Research and Development Program ("863" Program) of China (No. 2015AA034301) and the National Natural Science Foundation of China (No. 51501201).

\section{References}

[1] N. Ghaffour, Desalin. Water Treat. 5, 48 (2009)

[2] S.S. Xin, M.C. Li, Corros. Sci. 81, 96 (2014)

[3] K.V. Reddy, N. Ghaffour, Desalination 205, 340 (2007)

[4] N.M. Wade, Desalination 93, 343 (1993)

[5] M. Al-Shammiri, M. Safar, Desalination 126, 45 (1999)

[6] L.F. Greenlee, D.F. Lawler, B.D. Freeman, B. Marrot, P. Moulin, Water Res. 43, 2317 (2009)

[7] J.S. Lee, K. Fushimi, T. Nakanishi, Y. Hasegawa, Y.S. Park, Corros. Sci. 89, 111 (2014)

[8] S. Nagarajan, N. Rajendran, Corros. Sci. 51, 217 (2009)
[9] S.T. Kim, S.Y. Kim, I.S. Lee, Y.S. Park, M.C. Shin, Y.S. Kim, Corros. Sci. 53, 2611 (2011)

[10] D.H. Kang, H.W. Lee, Corros. Sci. 74, 369 (2013)

[11] M. Barteri, M.G. Mecozzi, I. Nembrini, Duplex Stainless Steels 94, Glasgow, Scotland, vol. 3, 1994, p. 60

[12] Z.Y. Zhang, H. Zhao, H.Z. Zhang, J. Hua, J. Jina, Corros. Sci. 22, 121 (2017)

[13] W.T. Tsai, J.R. Chen, Corros. Sci. 49, 3659 (2007)

[14] Y. Han, H. Wu, W. Zhang, D.N. Zou, G.W. Liu, G.J. Qiao, Mater. Des. 69, 230 (2015)

[15] J.W. Oldfield, B. Todd, Desalination 108, 27 (1996)

[16] A.U. Mahk, I. Andijani, A.M. Jamaluddin, S. Ahmed, Desalination 171, 289 (2005)

[17] B.P. Cai, Y.H. Liu, X.J. Tian, F. Wang, H. Li, R.J. Ji, Corros. Sci. 52, 3235 (2010)

[18] ASTM Standard G78, Standard Guide for Crevice Corrosion Testing of Iron-Base and Nickel-Base Stainless Alloy in Seawater and Other Chloride-Containing Aqueous Environments (2007)

[19] H. Gerengi, K. Darowicki, G. Bereket, P. Slepski, Corros. Sci. 51, 2573 (2009)

[20] ASTM Standard G61, Standard Test Method for Conducting Cyclic Potentiodynamic Polarization Measurements for Localized Corrosion Susceptibility of Iron-, Nickel-, or Cobalt-Based Alloys (2009)

[21] X. He, T. Mintz, JOM 60, 44 (2008)

[22] S. Wang, R.C. Newman, Corrosion 60, 448 (2004)

[23] W.S. Tait, An Introduction to Electrochemical Corrosion Testing for Practicing Engineers and Scientists (Pairodacs Publications, Wisconsin, 1994), p. 26

[24] K.J. Evabs, A. Yilmaz, S.D. Day, JOM 57, 56 (2005)

[25] R.M. Carranza, JOM 60, 58 (2008)

[26] J.S. Lee, M.L. Reed, R.G. Kelly, J. Electrochem. Soc. 151, B423 (2004)

[27] M.I. Abdulsalam, Corros. Sci. 47, 1336 (2005)

[28] M.I. Abdulsalam, H.W. Pickering, Corros. Sci. 41, 351 (1999)

[29] P.C. Pistorius, G.T. Burstein, Philos. Trans.: Phys. Sci. Eng. 341, 531 (1992)

[30] C. Pan, L. Liu, Y. Li, F.H. Wang, Corros. Sci. 73, 32 (2013)

[31] Y.Z. Yang, Y.M. Jiang, J. Li, Corros. Sci. 76, 163 (2013)

[32] L. Zhang, W. Zhang, Y. Jiang, B. Deng, D. Sun, J. Li, Electrochim. Acta 54, 5387 (2009)

[33] N. Rajendran, S. Rajeswari, J. Mater. Eng. Perform. 5, 46 (1996)

[34] G. Latha, N. Rajendran, S. Rajeswari, J. Mater. Eng. Perform. 6, 743 (1997)

[35] A.R. Brooks, C.R. Clayton, K. Doss, Y.C. Lu, J. Electrochem. Soc. 133, 2459 (1986)

[36] C.R. Clayton, Y.C. Lu, Corros. Sci. 29, 881 (1989)

[37] M.A. Ameer, A.M. Fekry, F. El-Taib, Heakal. Electrochim. Acta 50, 43 (2004)

[38] N. Boucherit, A. Hugot-le Goff, S. Joiret, Corrosion 48, 569 (1992)

[39] W.J. Tobler, S. Virtanen, Corros. Sci. 48, 1585 (2006)

[40] M. Bastidas, C.L. Torres, E. Cano, J.L. Polo, Corros. Sci. 44, 625 (2002)

[41] C.R. Clayton, Y.C. Lu, J. Electrochem. Soc. 133, 2465 (1986)

[42] I. Olefjord, B.O. Elfstrom, Corrosion 38, 46 (1982)

[43] P. Marcus, M.E. Bussell, Appl. Surf. Sci. 59, 7 (1992)

[44] A. Sadough Vanini, J.P. Audouard, P. Marcus, Corros. Sci. 36, 825 (1994)

[45] A. Swift, A.G. Paul, J.C. Vickerman, Surf. Interface Anal. 20, 27 (1993)

[46] R.D. Willenbruch, C.R. Clayton, M. Oversluizen, D. Kim, Y.C. Lu, Corros. Sci. 31, 179 (1990)

[47] J.J. Qi, B.Y. Huang, Z.H. Wang, H. Ding, J.L. Xi, W.T. Fu, J. Mater. Sci. Technol. 33, 1621 (2017) 